\title{
A EXCLUSÃO SOCIAL COMO REPRESENTAÇÃO LEGITIMADORA DA VIOLÊNCIA INSTITUCIONAL EM JESUS DE NAZARETH
}

\author{
Ariane LUCAS GUIMARÃES \\ Instituto Federal de Educação, Ciência e Tecnologia do Espírito Santo. Brasil. \\ arianeguimaraes@hotmail.com
}

Leonardo BIS DOS SANTOS

Instituto Federal de Educação, Ciência e Tecnologia do Espírito Santo. Brasil. leonardo.bis@ifes.edu.br

\section{RESUMO}

Pretende analisar introdutoriamente o conceito de exclusão social como síntese da construção do imaginário sobre a periferia urbana de Vitória-ES, mais especificamente o bairro Jesus de Nazareth. A ideia do discurso como instrumento de poder e justificação da violência institucional foi utilizada como um marco da representação social na análise de reportagens sobre o local. Estas foram selecionadas de um portal de jornal local, em que o nome do bairro aparecia. Nos resultados encontrados na pesquisa, separamos em grandes categorias, para análise dos casos de violência noticiados no bairro. Mais da metade das notícias estão nas temáticas: obras públicas/manutenção, ações policiais/ criminalidade, programações culturais e ações da comunidade/turismo local. Porém, ação policial/criminalidade apresenta uma expressividade pequena, já que mais da metade das notícias relatam os mesmos fenômenos. Tratam-se de duas grandes operações policiais no local em que nas duas o investimento humano e logístico não foi condizente com as apreensões. Entendemos que o estigma da pobreza na formação de exclusão social nas periferias urbanas tende a se intensificar no reconhecimento da linguagem simbólica, ou seja, na elaboração e reconhecimento de discursos. Tais ações só seriam justificáveis na periferia urbana pelo reconhecimento do discurso social do perigo que esses lugares representam. A efetivação da representação, ou dessa construção do imaginário, é a ação da violência institucionalizada pelo Estado, que reconhece e age de acordo com essa imagem social.

\section{PALAVRAS-CHAVE}

Jesus de Nazareth - Exclusão Social - Representação - Imaginário - Violência Institucional

\section{SOCIAL EXCLUSION AS REPRESENTATION LEGITIMATOR OF INSTITUTIONAL VIOLENCE IN JESUS DE NAZARETH}

\section{ABSTRACT}

It intends to analyze introductory the concept of social exclusion as a synthesis of the construction of the imaginary about the urban periphery of Vitória-ES, more specifically the neighborhood Jesus de Nazareth. The idea of discourse as an instrument of 
power and justification for institutional violence was used as a framework for social representation in the analysis of reports about the place. These were selected from a local newspaper portal, where the name of the neighborhood appeared. In the results found in the survey, we separated into large categories, for analysis of cases of violence reported in the neighborhood. More than half of the news are on the themes: public works/maintenance, police actions/crime, cultural programs and actions by the local community/tourism. However, police action/criminality has little expression, since more than half of the news reports report the same phenomena. These are two major police operations in the area where human and logistical investment in both were not consistent with the apprehensions. We understand that the stigma of poverty in the formation of social exclusion in urban peripheries tends to intensify in the recognition of symbolic language, that is, in the elaboration and recognition of discourses. Such actions would only be justified in the urban periphery by recognizing the social discourse of the danger that these places represent. The realization of representation, or this construction of the imaginary, is the action of violence institutionalized by the State, which recognizes and acts in accordance with this social image.

\section{KEY WORDS}

Jesus de Nazareth - Social Exclusion - Representation - Imaginary - Institutional Violence.

Recibido: $21 / 04 / 2020$

Aprobado: 10/07/2020

\section{INTRODUÇÃO}

A constituição histórica da ocupação do morro de Jesus de Nazareth desde os primórdios remete a luta por moradia. Enquanto toda a região de Bento Ferreira, Praia do Canto e outros bairros afins eram preparados para que essa nova configuração social de Vitória-ES se desenhasse conforme os planos traçados pelo desenvolvimento do lema do progresso - ou seja, eram preparados para que pessoas específicas o ocupassem (a especulação imobiliária é um mecanismo que controla esse zoneamento) - os trabalhadores dessas novas regiões, invisibilizados pelo cotidiano do trabalho intermitente das cidades procuraram fixar seus lares em locais próximos de onde trabalhavam, como foi o caso de Jesus de Nazareth, ou de zonas distantes ou inabitadas da cidade. Esse quadro demonstra e remonta a história da capital capixaba e a ocupação dos morros e zonas de manguezais: a mão de obra chamada pelo "desenvolvimento" deveria se desdobrar para fixar suas moradias. $O$ inchamento do centro urbano da capital e as novas zonas de expansão destinadas a uma parcela social específica legou aos trabalhadores que construíam essa nova cidade procurar esses espaços. Assim, o estigma da pobreza e a imposição da segregação social, constituíram a cidade aos moldes do que pode ser lida hoje. Os morros, as favelas, as comunidades, os manguezais, todos contam uma luta histórica pelo direito de existência, por ser reconhecido socialmente como 
cidadão de direitos, ser humano. Os santos, mártires e nomeação de lutas em que esses bairros foram batizados já nos indicam isso: Resistência, Joana D'arc, São Benedito, São Pedro, Jesus de Nazareth entre tantos outros.

Desse modo, o traçado histórico demonstra que as lógicas impostas pelo modelo sistêmico de sociedade em que vivemos criam movimentos de exclusão social. Mas, como defende Antônio Sabadini (2001) a complexidade das relações sociais pode criar possibilidades de integração, mesmo em meio a realidades de exclusão.

Por isso mesmo não assistimos a um processo unidimensional e inelutável de exclusão social. Existe um campo de ação possível para a integração social, cuja importância pode variar em cada cidade, dependendo de fatores demográficos, sociológicos, econômicos e geográficos. Em particular atribuímos grande importância à modificação em curso na escala espacial da segregação, isto é, às mudanças tanto no tamanho das áreas ou bairros socialmente homogêneos quanto na distância média entre as diferentes áreas socioeconômicas e entre estas e os centros de atividade. Por isso também, as políticas urbanas, ainda que capazes de afetar inadvertida ou intencionalmente tal padrão geográfico de segregação, podem incidir sobre a combinação entre exclusão e integração sociais (p. 165).

Assim, nosso trabalho se propõe a analisar a representação social do bairro de Jesus de Nazareth em Vitória-ES através da divulgação midiática desse espaço urbano. Procurando entender os mecanismos de exclusão social de diferentes formas. Além de tratar desta categoria específica - exclusão social - entendida também como representação social, portanto, construída dentro de um processo histórico que constrói e reconstrói o imaginário urbano de Vitória-ES.

\section{REPRESENTAÇÃO E RECONHECIMENTO SOCIAL}

Representação social como categoria está necessariamente ligada ao imaginário, trata-se de sua materialização nas relações sociais. Para compor o campo teórico da construção do imaginário e do que a partir dele é criado procuramos alguns autores que nos serviram de base para o desenvolvimento desse trabalho. Castoriadis (1982) conceitua o imaginário, o simbólico e as representações sociais. A partir desse autor, entendemos que as instituições [sociais], que estão no mundo do social-histórico, não se reduzem ao simbólico, mas só podem existir por meio deste (p. 142). Mas o que seriam essas instituições? O autor descreve que

A instituição é uma rede simbólica, socialmente sancionada, onde se combinam em proporções e em relações variáveis um componente funcional e um componente imaginário. A alienação éa autonomização e a dominância do momento imaginário na instituição que propicia a autonomização e a dominância da instituição relativamente à sociedade. Esta autonomização da instituição exprime-se e encarna-se na materialidade da vida social, mas supõe sempre também que a sociedade vive suas relações com suas instituições à maneira do imaginário, ou seja, não reconhece no imaginário das instituições seu próprio produto (CASTORIADIS, 1982, p. 159). 
Na segunda parte de A Instituição Imaginária da Sociedade (1995), Castoriadis vai definir seu entendimento do imaginário, diferenciando-o do sentido corrente de algo falso, como invenção, como engano - e situando-o como fazendo parte indistinguível do que implica ser humano. Caracterizando as instituições sociais, ele afirma que tudo de que se fala, tudo o que se apresenta para e pelos indivíduos está associado a uma rede simbólica, um simbólico que obviamente está na linguagem, mas que também está nas instituições. Aquilo que determina uma instituição, o que se produz e o que se fala ali, não se explica perfeitamente pela sua funcionalidade, ou pelas consequências lógicas destes atos/palavras, mas a ultrapassa, isto é, comporta algo mais que escapa à ordenação simbólica. Os símbolos institucionais, aquilo que representam, não são assim instituídos apenas racionalmente e também não o são naturalmente, mesmo que apoiados de alguma forma na realidade. Isto que não é redutível ao simbólico, mas que a ele está necessariamente associado, é uma primeira aproximação do que Castoriadis irá chamar de imaginário.

Deste modo, podemos entender a construção cultural das sociedades, suas redes simbólicas na tessitura dos sentidos que compõe a leitura da realidade. A institucionalização das relações, mesmo que nem sempre sejam percebidas, nos chama a atenção pelo que é pelo que poderia ser - possibilidades ou potencialidades, se o preferirmos. Desnudar o que está posto é, assim, uma possibilidade de criar novos caminhos, outros sentidos. Bourdieu (2004) conceitua assim o poder simbólico, na luta pelo reconhecimento entre os grupos sociais. Trata-se de um poder que naturaliza as instituições, e, portanto, as desigualdades impostas por essa relação de força.

O poder simbólico como poder de construir o dado pela enunciação, de fazer ver e fazer crer, de confirmar ou de transformar a visão do mundo e, deste modo, a acção sobre o mundo, portanto o mundo; poder quase mágico que permite obter o equivalente daquilo que é obtido pela força (física ou econômica), graças ao efeito espécífico de mobilização, só se exerce se for reconhecido, quer dizer, ignorado como arbitrário. Isto significa que o poder simbólico não reside nos "sistemas simbólicos" em forma de uma "illocutionary force" mas que se define numa relação determinada - e por meio desta - entre os que exercem o poder e os que Ihe estão sujeitos, quer dizer, isto é, na própria estrutura do campo que se produz e se reproduz a crença. [...]

O poder simbólico, poder subordinado, é uma forma transformada, quer dizer, irreconhecível, transfigurada e legitimada, das outras formas de poder (p. 14).

\section{A CATEGORIA DE EXCLUSÃO SOCIAL}

Falar de excluídos ou de exclusão social numa análise demográfica é uma tarefa difícil pela diversificação do campo social, teórico e do mundo do trabalho, como confirma Ana Maria Goldani. 
Do ponto de vista metodológico, as dificuldades aumentam ainda mais quando se trata de construir a categoria excluídos. A fragmentação, heterogeneidade e diversificação que hoje marcam o mundo do trabalho, somadas às diferenças Norte-Sul e de gênero, dificultam o uso de categorias estatísticas fixas para tratar dos incluídos e excluídos (GOLDANI, 2001, p. 48).

Assim, a via da representação se mostra o caminho mais seguro para nosso recorte social. A análise qualitativa, aliada à métodos quantitativos, nos proporciona ferramentas que serão empregadas em nosso objeto de pesquisa.

O estudo das representações sociais objetiva a percepção do real utilizando categorias que possibilite o entendimento da construção da realidade social. "As representações do mundo social, assim construídas, são sempre determinadas pelos interesses do grupo que as forja. Daí a relação entre o discurso e a posição de quem o utiliza" (LIMA, 2005, p. 65).

Sobre isso, a construção histórica da representação e as possibilidades de leitura de mundo CHARTIER discorre:

As percepções do social não são de forma alguma discursos neutros: produzem estratégias e práticas (sociais, escolares, políticas) que tendem a impor uma autoridade à custa de outros, por elas menosprezadas, a legitimar um projeto reformador ou a justificar, para os próprios indivíduos, as suas escolhas e condutas. Por isso, essa investigação sobre as representações supõe-nas como estando sempre colocadas num campo de concorrências e de competições cujos desafios se enunciam em termos de poder e de dominação. As lutas de representações têm tanta importância como as lutas econômicas para compreender os mecanismos pelos quais um grupo impõe, ou tenta impor, a sua concepção do mundo social, os valores que são seus, e o seu domínio (1987, p.17).

Desse modo, as lutas de dominação e poder se encontram no cerne da produção de exclusão. Assim, a pobreza por si só não é o que produz exclusão social, mas o sistema político, social e econômico que produz a pobreza. $E$, através de mecanismos simbólicos de controle, esse poder se exerce numa força hierarquizante, capaz de produzir dominantes e dominados, desigualdades e discursos legitimadores dessas desigualdades.

Utilizamos o percurso do pesquisador Mário Hélio Trindade Lima, em Exclusão social: representações sociais da pobreza no Brasil, para compreender a dinâmica da exclusão social, numa linha de lutas de poder no estabelecimento de grupos, como de estabelecidos e outsiders ${ }^{1}$. Seguindo a intenção de analisar o discurso

1 Trata-se da obra homônima de Norbert Elias de caráter etnográfico em que estuda a dinâmica do exercício da dominação de grupos. Na introdução do livro o autor já explica o que seria esse poder capaz de assentar estabelecidos e criar outsiders:

"A descrição de uma comunidade da periferia urbana apresentada neste livro mostra uma clara divisão, em seu interior, entre um grupo estabelecido desde longa data e um grupo mais novo de residentes, cujos moradores eram tratados pelo primeiro como outsiders. O grupo estabelecido cerrava fileiras contra eles e os estigmatizava, 
sobre a pobreza urbana com a utilização de estereotipias, que compartilhadas socialmente tem o poder de lançar esses grupos "num espaço anômico, excluindoos dos modelos econômico ou normativo" (LIMA, 2005, p. 69).

O compartilhamento de imagens do olhar do não pobre sobre os pobres tende a classificar, reificar, notar a visão dos grupos estabelecidos sobre os dominados. Criando o estranhamento a ameaça que este grupo pode oferecer.

Se observarmos as diversas imagens construídas, historicamente, a respeito dos pobres urbanos e de seus espaços de moradia vamos encontrar, como características distintas, a ausência de regras e de valores dominantes, o exemplo de desordeiros que desrespeitam as leis, que não seguem as regras do mundo normal do trabalho, em suma, como desadaptados sociais. Seres, em geral, inferiores e, particularmente, sujos, dotados das qualidades distintivas de sua posição social, sem boas maneiras, sem princípios éticos do trabalho, sujeitos ao controle social sob pena de ameaçar a ordem dominante. $O$ discurso sobre os pobres é o discurso do poder, das vozes autorizadas a dizer o que o pobre é, a apontar suas características para fazê-lo ser reconhecido por certos atributos que faltam a ele, e que os constituem como uma classe social. É um discurso que visa reconhecer as características do inimigo para poder, então, ataca-lo. É um discurso estratégico, com o objetivo de dominar o seu destino e o seu território, para transformá-lo e impor um novo rumo e uma nova forma espacial, para organizar o desorganizado, para estabelecer a ordem num terreno de desordem, para difundir novos valores em substituição aos valores não desejáveis, em suma, um discurso que prega a ação, a interdição de um determinado estado de coisas. É, portanto, um discurso dominante, calcado em estereótipos e imagens negativas que arrasta a vontade de poder. Um movimento de miragem que observa o pobre e que o descreve pelos seus traços semelhantes, de certa forma inventando o seu mundo como um mundo de casos idênticos, essa chapa de generalidade, de moralidade, de indiferença, que pesa sobre nosso discurso coletivo (LIMA, 2005, p. 70).

Assim, trataremos da análise midiática sobre o bairro Jesus de Nazareth, sua reificação discursiva e as possibilidades de rupturas e novos processos de reconhecimento social. Ou seja, a criação de novos discursos.

\footnotetext{
de maneira geral, como pessoas de menor valor humano. Considerava-se que lhes faltava a virtude humana superior - o carisma grupal distintivo - que o grupo dominante atribuía a si mesmo.

[...]

Essa é a auto-imagem normal dos grupos que, em termos do seu diferencial de poder, são seguramente superiores a outros grupos interdependentes. Quer se trate de quadros sociais, como os senhores feudais em relação aos vilões, os 'brancos' em relação aos 'negros', os gentios em relação aos judeus, os protestantes em relação aos católicos e vice-versa, os homens em relação às mulheres (antigamente), os Estados nacionais grandes e poderosos em relação a seus homólogos pequenos e relativamente impotentes, quer, como no caso de Winston Parva, de uma povoação da classe trabalhadora, estabelecida desde longa data, em relação aos membros de uma nova povoação de trabalhadores em sua vizinhança, os grupos mais poderosos, na totalidade desses casos, vêem-se como pessoas 'melhores', dotadas de uma espécie de carisma grupal, de uma virtude específica que é compartilhada por todos os seus membros e que falta aos outros. Mais ainda, em todos esses casos, os indivíduos 'superiores' podem fazer com que os próprios indivíduos inferiores se sintam, eles mesmos, carentes de virtudes - julgando-se humanamente inferiores" (ELIAS, 2000, p. 19).
} 


\section{JESUS DE NAZARETH}

O Morro de Bento Ferreira, como era conhecido o bairro, ganhou ligamentos terrestres após a expansão dos aterros de Vitória-ES. Os relatos dos moradores é que a primeira família do bairro chegou por volta da década de 50 . Mesmo após vários conflitos com a prefeitura e com a polícia para tentativa de desocupação do local, os moradores ali resistiram em anos de luta, articulando suas resistências em organização coletiva² ${ }^{2}$ como pode ser observado no site da Prefeitura Municipal de Vitória, em que conta essa história

[o] processo de ocupação, até o final dos anos 70, foi caracterizado como conflituoso. Nos anos de 1955/1957, o então Prefeito do Município de Vitória, Dr. Adelpho Poli Monjardim, preocupado com o adensamento da área, determinou que a mesma fosse fiscalizada. O controle era efetuado por fiscais que chegavam a área acompanhados por policiais para executar a demolição dos barracos e expulsar os moradores. Nessas ocasiões ocorriam resistências da comunidade em defesa da posse das habitações e seus respectivos lotes. Foi nesta época que se deu a morte do fiscal da Prefeitura.

A intensificação dos assentamentos ocorreu na década de 70, agravandose a forma desordenada da ocupação do morro. Nesse período foi concretizada uma política de expulsão das famílias, onde "barracos" foram derrubados e incendiados. Mais uma vez, houve confronto da comunidade com policiais, ocorrendo a morte de um morador.

Tal ao ocorrido, o esforço individual pela moradia transformou-se em uma luta coletiva, em busca da permanência dos moradores na área e legalização dos loteamentos ${ }^{3}$.

Porém, o estigma da pobreza e do distanciamento dessa periferia cercada pela zona nobre, ainda lhe conferia características insulares. Falamos agora de um distanciamento e estranhamento social.

Tão claro quanto a representação da exclusão da periferia, a resistência coletiva produz tantos outros significados. Tece outras possibilidades, outras narrativas. Histórias que são resgatadas e elevadas às memórias coletivas, portanto, mecanismos de lutas de resistência do grupo. Assim a defesa de Antônio Sabadini (2001) da complexidade das relações sociais poder criar possibilidades de integração, mesmo em meio a realidades de exclusão, torna-se perceptível nesse movimento das práticas sociais.

Em análise a um jornal impresso capixaba disponível em meio digital ${ }^{4}$ procuramos por notícias do bairro. Ao digitar o nome, encontramos 103 resultados, com a datas limites de 29 de novembro de 2018 a 03 de julho de 2015. Temos ciência

2 Informações da página da Prefeitura Municipal de Vitória. Disponível em: <http://legado.vitoria.es.gov.br/ regionais/bairros/regiao3/jesusdenazareth.asp>. Acesso em 07 dez de 2018.

3 Idem.

4 Trata-se do jornal Gazeta Online. Esse jornal foi escolhido por ser uma das mídias capixabas mais antigas e por seu alcance e expressividade. Disponível em: <https://www.gazetaonline.com.br/pesquisar?query=jesus\%20 de\%20nazareth\&sort=maisRecentes>. Acesso em: dez de 2018. 
do curto recorte temporal, mas que nos permite visualizarmos alguns dados interessantes. Desprezamos notícias gerais como abastecimento de água na região metropolitana, colunas sobre políticas, mudanças no PDU, vacinação, eleições etc. Assim, foram selecionadas 72 notícias que falavam diretamente sobre o bairro. Para melhor visualização, as dividimos em abordagens temáticas, conforme pode ser observado no quadro:

Tabela 1. Temáticas selecionadas e número de reportagens encontrados

\begin{tabular}{|c|c|}
\hline TEMÁTICAS & No DE REPORTAGENS \\
\hline Ações policiais/criminalidade & 14 \\
\hline Acidentes & 5 \\
\hline Obras públicas/manutenção & 15 \\
\hline Protestos/críticas às ações policiais & 6 \\
\hline Programações culturais & 9 \\
\hline Saúde & 6 \\
\hline Educação & 5 \\
\hline Ações da comunidade/turismo local & 9 \\
\hline Política & 2 \\
\hline História & 1 \\
\hline Total & 72 \\
\hline
\end{tabular}

Elaborada pelos autores, 2019.

A formulação das escolhas temáticas, às vezes juntando ações e nome diferentes, como ações policiais e criminalidade foram colocados na mesma categoria pois essas ações policiais foram justificadas pela criminalidade no local, de acordo com as próprias fontes da polícia. Como pode ser observado no trecho a seguir de uma notícia:

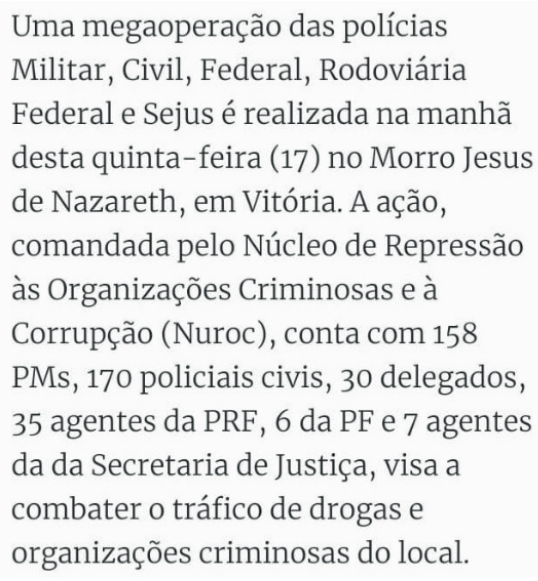

Figura 1. Trecho da reportagem "Operação policial em Jesus de Nazareth fecha Beira-Mar" Fonte: Jornal eletrônico Gazeta Online ${ }^{5}$. Reportagem datada de 17 de ago de 2017.

5 Disponível em: <https://www.gazetaonline.com.br/noticias/cidades/2017/08/operacao-policial-em-jesus-de- 
Assim também as ações da comunidade e turismo local foram colocados na mesma categoria porque as ações de turismo local se enquadram enquanto práticas comunitárias (conforme pode ser observado abaixo). Essa linguagem se repete na formulação de outras categorias (obras públicas/manutenção e protestos/críticas às ações policiais).

\author{
Cidades \\ Belezas da Capital \\ Rapel e canoa havaiana \\ levam turistas a Jesus \\ de Nazareth, em Vitória \\ Moradores do bairro são guias de projeto que \\ quer mostrar história e belas paisagens para \\ visitantes

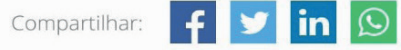 \\ Publicado em 09/08/2017 às 06h43 \\ (.) Atualizado em $10 / 08 / 2017$ às $01 \mathrm{~h} 20$
}

Figura 2. Reportagem sobre turismo local como ação da comunidade Fonte: Jornal eletrônico Gazeta Online ${ }^{6}$

Dentro no nosso quadro as temáticas que mais somam resultados são respectivamente: obras públicas/manutenção (15 resultados), ações policiais/ criminalidade (14 resultados), programações culturais (9 resultados) e ações da comunidade/turismo local (9 resultados). Essas temáticas juntas expressam mais de $50 \%$ do conteúdo analisado.

Porém, o que nos chamou a atenção foi que o quesito ação policial/criminalidade tem uma expressividade muito pequena, já que das 14 ocorrências, oito reportagens falam dos mesmos fenômenos. No ano de 2017 o bairro foi cercado (via área, terrestre e pelo mar) por uma grande força policial por conta do combate ao tráfico e às organizações criminosas, conforme comprova a figura 1 . O outro fenômeno aconteceu neste ano (2018), em que um gari da prefeitura municipal de Vitória foi atingido por um tiro no tornozelo. $O$ interessante é que as versões dos relatos se contradizem ${ }^{7}$. $\mathrm{O}$ que essas duas grandes ações policiais têm em

nazareth-fecha-beira-mar-1014090508.html>. Acesso em: dez de 2018.

6 Disponível em: <https://www.gazetaonline.com.br/noticias/cidades/2017/08/rapel-e-canoa-havaiana-levamturistas-a-jesus-de-nazareth-em-vitoria-1014087494.html>. Acesso em: dez de 2018.

7 Na versão oficial da polícia quando os policiais descaracterizados chegaram ao local, criminosos se aproximaram atirando e os policiais revidaram. O gari, que segundo os policiais, estava atrás da viatura, foi atingido por tiros disparados pelos criminosos e foi socorrido logo depois. Essa versão pode ser observada em: <https://www. gazetaonline.com.br/noticias/policia/2018/09/gari-e-baleado-durante-troca-de-tiros-entre-pm-e-traficantesem-vitoria-1014149129.html>. Acesso em: dez de 2018.

Porém, o gari relatou uma versão totalmente contrária à dada pela polícia. Para conferência, reproduzimos aqui o trecho completo da reportagem:

"Parecia um campo de guerra". Assim o gari definiu o momento de tensão vivido durante uma ação da Polícia Militar contra traficantes, que aconteceu no bairro Jesus de Nazareth, em Vitória, na manhã desta sexta-feira (21). Ele foi atingido por uma bala perdida no tornozelo e, apesar da lesão, não precisou passar por uma cirurgia. O homem contou ao jornalista Rodrigo Maia, da TV Gazeta, que viu um carro descaracterizado chegando ao local, quando quatro policiais desceram do veículo. Ele afirmou que os militares já chegaram atirando contra 
comum poderia ser descrito como abuso de poder legitimado pela violência institucional nas ações do Estado na representação social da periferia.

A legitimação da violência institucional pode ser verificada pela ausência de outros grandes casos de violência (tráfico, roubo, assassinato) no local. Aliás, das notícias analisadas nenhuma fez menção a casos de homicídio no bairro. Não se trata da negação das atividades criminosas no local, mas de sua pouca expressividade para justificar tais ações do Estado.

Nossa tese é comprovada quando vamos verificar o que a comunidade pensa sobre si mesma. Uma pesquisa realizada pelo Sebrae para a inauguração da nova sede em 2017, descreve o derredor do órgão. Entre os locais pesquisados o bairro Jesus de Nazareth evidenciou os seguintes resultados sobre a segurança pública: dos 395 entrevistados, 6,84\% avaliaram como ótimo, 41,52\% como bom, 31,14\% como regular, 7,09\% como ruim, 12,15\% como péssimo e 1,27\% não respondeu. Sobre a pergunta: você ou alguém da sua família tiveram problemas de segurança nos últimos 12 meses? 90\% responderam que não tiveram problemas, $5 \%$ disseram ter sofrido com assalto ou furto e $1 \%$ apontou o tráfico de drogas.

Como essas ações policiais podem ser justificadas? Entendemos que o estigma da pobreza na formação de exclusão social nas periferias urbanas tende a se intensificar no reconhecimento da linguagem simbólica, ou seja, na elaboração e reconhecimento de discursos. Tais ações só seriam justificáveis na periferia pelo reconhecimento do discurso social do perigo que esses lugares representam. Sobre a apropriação do discurso, Marilena Chauí (1982, p. 7) afirma que:

O discurso competente confunde-se, pois, com a linguagem institucionalmente permitida ou autorizada, isto é, um discurso no qual os interlocutores já foram previamente reconhecidos como tendo o direito de falar e ouvir, no qual os lugares e as circunstâncias já foram predeterminadas para que não seja permitido falar e ouvir, enfim, no qual o conteúdo e a forma já foram autorizados segundo os cânones da esfera de sua própria existência (Apud LIMA, 2005, p. 77).

\footnotetext{
os suspeitos que estavam no morro. "Chegou um carro, um EcoSport, e ficou parado. Nisso, os meninos até foram ver quem era. Eram uns quatro policiais, que já desceram atirando. Os meninos deitaram no chão e eles continuaram atirando", contou.

Durante a operação, assustado, o gari tentou se esconder atrás de um poste. "O primeiro tiro que eles deram tinha me atingido. Eu me escondi atrás do poste e comecei a gritar, mas mesmo assim eles continuaram atirando. Meu colega tentou me socorrer também. Os policiais pediram pra eu ficar deitado, mas graças a Deus um morador do morro me ajudou, me socorreu".

Segundo a vítima, no momento da ação, não tinha muitas pessoas na rua. "Praticamente não tinha muita gente na rua não. Mas depois chegou muita gente porque viu a gente gritando. Graças a Deus não foi algo mais grave, eu não passei por uma cirurgia mais delicada", disse.

Disponível em: <https://www.gazetaonline.com.br/noticias/policia/2018/09/parecia-um-campo-de-guerra-diz-gari-baleado-em-vitoria-1014149194.html>. Acesso em: dez de 2018.
} 


\section{CONCLUSÃO}

É no campo simbólico que a produção social da violência simbólica se dá. "A violência simbólica é uma violência que se exerce com a cumplicidade tácita dos que a sofrem e também, com freqüência, dos que a exercem, na medida em que uns e outros são inconscientes de exercê-la ou de sofrê-la" (BOURDIEU, 1997, p. 22).

Dentro dessa leitura o sociólogo ainda defende que o Estado é a base das classificações sociais:

"o Estado é a posse do monopólio da violência física e simbólica": "[...] O Estado é o que funda a integração lógica e a integração moral do mundo social e, por aí, o consenso fundamental sobre o sentido do mundo que é a condição mesma dos conflitos a propósito do mundo social" (2012, p.15). Daí sua afirmação de um golpe de força simbólica na gênese do Estado: "O golpe de Estado do qual nasceu o Estado [...] testemunha um golpe de força simbólico extraordinário que consiste em fazer aceitar universalmente, nos limites de um certo território..., a ideia de que todos os pontos de vista não são válidos e que há um ponto de vista que é a medida de todos os pontos de vista, dominante e legítimo" (2012, p. 116, apud SANTOS, 2015, p. 184).

Desse modo, nosso trabalho se motivou para trazer outras narrativas, denunciar o que está posto, renunciar às representações de exclusão. Que negam em si a humanidade daqueles que excluem. Ou nas palavras do professor Mário Hélio Trindade de Lima:

A noção de exclusão está, pois, fundada em valores, presentes na concepção do que seja uma sociedade igual, justa e livre para o homem, característicos do ideário moderno. E vem carregada de valores negativos e estigmatizantes. Os excluídos são desnecessários economicamente já que, numa sociedade cada vez mais técnica, os postos de trabalho tendem a ser cada vez mais reduzidos, não ocupam nenhum lugar no sistema produtivo e no espaço social, além de ameaçar a coesão da ordem social e o ideário de democracia da ordem política. Os excluídos são vistos como não sujeitos de sua ação, sem qualquer possibilidade de formulação de um projeto político, sujeitos à violência sem direção e, portanto, alvo privilegiado de intervenções do aparelho repressivo, da Igreja, do Estado e da sociedade civil organizada (2005, p. 82).

A exclusão social existe em meio à sua negação. Trazer essas novas realidades à tona não é um trabalho heroico do pesquisador. Mas evidenciar outras vozes, realidades, significações, sentidos e representações é uma tarefa humana. Trabalho necessário para criar rupturas na legitimação da violência física e simbólica do Estado síntese da estrutura social em que vivemos. 


\section{REFERÊNCIAS}

BOURDIEU, Pierre. 0 poder simbólico. 7a ed. Rio de Janeiro: Bertrand Brasil, 2004. Sobre a televisão. Rio de Janeiro: Jorge Zahar Ed., 1997.

CASTORIADIS, Cornelius. A instituição imaginária da sociedade. Rio de Janeiro: Paz e Terra, 1982.

CHARTIER, Roger. A história cultural: entre práticas e representações. Lisboa: Memória e Sociedade/ Difel, 1987.

ELIAS, Norbert. Os estabelecidos e os outsiders: sociologia das relações de poder a partir de uma pequena comunidade. Rio de Janeiro: Jorge Zahar Ed., 2000.

FERNANDES, Ana Cristina; LACERDA, Norma; PONTUAL, Virginia (org.). Desenvolvimento, planejamento e governança. Rio de Janeiro: Letra Capital: Anpur, 2015.

GALEANO, Eduardo H. As veias abertas da América Latina. Porto Alegre: L\&PM, 2019.

GOLDANI, Ana Maria. Demografia da exclusão: construção de uma agenda da perspectiva do Sul. In: OLIVEIRA, Maria Coleta (org.). Demografia da exclusão social. Campinas: Editora da Unicamp, Nepo, 2001.

LIMA, Mário Hélio Trindade. Exclusão social: representações sociais da pobreza no Brasil. Vitória: EDUFES, 2005.

PIRES, Roberto Rocha C. (org.). Implementando desigualdades: reprodução de desigualdades na implementação de políticas públicas. Rio de Janeiro: Ipea, 2019.

SABATINI, Francisco. Transformação urbana e dialética entre integração e exclusão social: reflexões sobre as cidades latino-americanas e o caso de Santiago do Chile. In: OLIVEIRA, Maria Coleta (org.). Demografia da exclusão social. Campinas: Editora da Unicamp, Nepo, 2001.

SANTOS, José Vicente Tavares do. A violência simbólica: o Estado e as práticas sociais, Revista Crítica de Ciências Sociais, n.108, 2015, p. 183-190.

SANTOS, José Vicente Tavares dos. A violência simbólica: o Estado e as práticas sociais. Revista Crítica de Ciências Sociais [Online], 108 | 2015, posto online no dia 16 dezembro 2015, consultado o 22 setembro 2020. URL : http:// journals.openedition.org/rccs/6169; DOI : https://doi.org/10.4000/rccs. 6169 